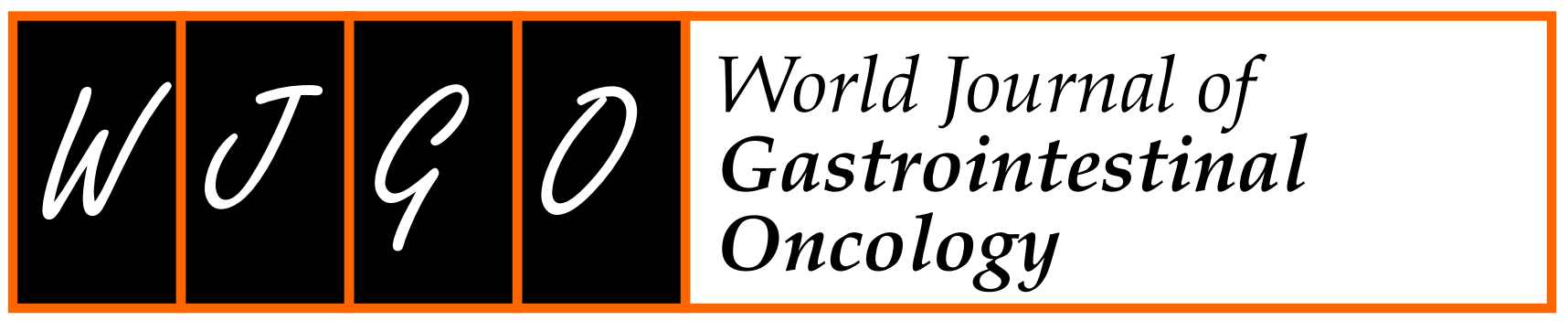

\title{
Targeted agents for second-line treatment of advanced hepatocellular carcinoma
}

\author{
Nicola Personeni, Tiziana Pressiani, Silvia Bozzarelli, Lorenza Rimassa
}

\author{
ORCID number: Nicola Personeni \\ (0000-0002-7995-272X); Tiziana \\ Pressiani (0000-0001-6919-1536); \\ Silvia Bozzarelli \\ (0000-0002-8118-7342); Lorenza \\ Rimassa (0000-0001-9957-3615).
}

Author contributions: Personeni N, Pressiani T, Bozzarelli S and Rimassa L performed data research; Personeni N, Pressiani T, Bozzarelli S and Rimassa L wrote the paper; Personeni N performed the critical revision of the manuscript.

\section{Conflict-of-interest statement:} Personeni $\mathrm{N}$ has received lecture fees from AbbVie and Gilead, and travel expenses from ArQule. Rimassa L has received consulting fees from Lilly, Bayer, Sirtex Medical, ArQule, Exelixis, Ipsen, Celgene, Eisai, and Roche, lecture fees from AstraZeneca, AbbVie, and Gilead, and travel expenses from ArQule and Ipsen. Pressiani T and Bozzarelli $S$ have declared no conflict of interests. The authors have no other relevant affiliations or financial involvement with any organization or entity with a financial interest in or financial conflict with the subject matter or materials discussed in the manuscript apart from those disclosed. No writing assistance was utilized in the production of this manuscript.

Manuscript source: Invited manuscript

Received: April 29, 2019

Peer-review started: May 9, 2019

First decision: June 4, 2019

Revised: July 25, 2019
Nicola Personeni, Tiziana Pressiani, Silvia Bozzarelli, Lorenza Rimassa, Medical Oncology and Hematology Unit, Humanitas Cancer Center, Humanitas Clinical and Research Center, IRCCS, Rozzano 20089, Milan, Italy

Nicola Personeni, Lorenza Rimassa, Department of Biomedical Sciences, Humanitas University, Pieve Emanuele 20090, Milan, Italy

Corresponding author: Lorenza Rimassa, MD, Associate Professor, Medical Oncology and Hematology Unit, Humanitas Cancer Center, Humanitas Clinical and Research Center, IRCCS, via Manzoni 56, Rozzano 20089, Department of Biomedical Sciences, Humanitas University, Pieve Emanuele 20090, Milan, Italy. lorenza.rimassa@hunimed.eu Telephone: +39-2-82244573

Fax: $+39-2-82244590$

\section{Abstract}

Over the past ten years, sorafenib, a multikinase inhibitor, has been the standard of care for patients with unresectable hepatocellular carcinoma (HCC) and wellpreserved liver function. Recently, lenvatinib, a different multikinase inhibitor, was shown to be non-inferior to sorafenib, in terms of survival, while all other agents previously tested failed to prove non-inferiority (or superiority) when compared to sorafenib. Similarly, in the second-line setting, most investigational drugs failed to provide better survival outcomes than placebo. However, in the last 2 years three positive phase III trials have been published in this setting. The RESORCE trial, a phase III study evaluating regorafenib in HCC patients who experienced disease progression after first-line treatment with sorafenib, showed better outcomes with regorafenib compared to placebo. More recently, the phase III CELESTIAL trial demonstrated the superiority of cabozantinib, a multikinase inhibitor targeting vascular endothelial growth factor receptor, MET, and AXL, vs placebo in the second- and third-line setting in patients progressing on or intolerant to sorafenib. The survival benefits of a sustained anti-angiogenic inhibition were demonstrated also with ramucirumab in the phase III REACH-2 trial in patients previously treated with sorafenib and who had high baseline alpha-fetoprotein levels. Overall, the adverse events reported in these trials were in line with the known safety profiles of the tested agents. After nearly a decade of a certain degree of stagnation, we are now witnessing a period of novel therapeutic advances with multikinase inhibitors and monoclonal antibodies that will likely change the treatment scenario of HCC.

Key words: Hepatocellular carcinoma; Advanced-metastatic; Second-line; Third-line; 
Accepted: August 27, 2019

Article in press: August 28, 2019

Published online: October 15, 2019

P-Reviewer: Choo SP, Cidon EU

S-Editor: Tang JZ

L-Editor: Filipodia

E-Editor: Qi LL

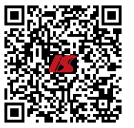

Regorafenib; Cabozantinib; Ramucirumab; Angiogenesis; Multikinase inhibitor; MET; AXL; Vascular endothelial growth factor receptor 2

CThe Author(s) 2019. Published by Baishideng Publishing Group Inc. All rights reserved.

Core tip: During the last decade, sorafenib, a multikinase inhibitor, has emerged as the only systemic agent available for the treatment of patients with unresectable hepatocellular carcinoma. However, in recent years, lenvatinib, which is a different multikinase inhibitor, was shown to be non-inferior compared to sorafenib. Despite several negative phase III trials, novel drugs with similar, but not overlapping, properties have been recently shown to improve patient outcomes, thereby confirming the role of sustained anti-angiogenic inhibition in further lines of treatment. Here, we will discuss the results of the positive phase III trials of regorafenib, cabozantinib, and ramucirumab in patients failing sorafenib.

Citation: Personeni N, Pressiani T, Bozzarelli S, Rimassa L. Targeted agents for second-line treatment of advanced hepatocellular carcinoma. World J Gastrointest Oncol 2019; 11(10): 788-803

URL: https://www.wjgnet.com/1948-5204/full/v11/i10/788.htm

DOI: https://dx.doi.org/10.4251/wjgo.v11.i10.788

\section{INTRODUCTION}

Liver cancer ranks second among major causes of cancer-related deaths globally. In particular, hepatocellular carcinoma (HCC) roughly represents $90 \%$ of all primary liver cancers with 800000 new cases reported yearly ${ }^{[1]}$. In more than $80 \%$ of patients, cirrhosis is a predisposing condition ${ }^{[2]}$, often related to prior infection with hepatitis $\mathrm{B}$ virus (HBV), hepatitis $\mathrm{C}$ virus (HCV), or alcohol abuse. Less frequently, HCC may also arise in a non-cirrhotic liver as a consequence of HBV genotoxic effects, nonalcoholic steatohepatitis (in patients with metabolic syndrome and diabetes), or malignant transformation of a hepatocellular adenoma.

Even under rigorous surveillance programs, a sizeable proportion of patients are often diagnosed at a stage not amenable to potentially curative approaches ${ }^{[3]}$, thereby prompting the search for palliative treatments.

In recent years, transcriptome analyses have allowed to increase our understanding of HCC complexity with the identification of a proliferation class and a nonproliferation one ${ }^{[2,4]}$. Both classes display recurrent genetic alterations that affect deregulated pathways relevant to cellular homeostasis, senescence, proliferation, and differentiation. Although the ultimate goal of such advances is to inform future treatment strategies, none among driver mutations leading to oncogenic addiction in HCC is thus far considered as actionable ${ }^{[5]}$.

On top of that, additional hurdles that hamper the development of personalized therapies lie within a substantial intra- and inter-tumor heterogeneity, that result from an admixture of mature hepatocytes and hepatic progenitor cells, both contributing to chronic inflammation, advanced fibrosis, and eventually cancer development ${ }^{[6]}$.

Despite the obvious disappointment following the results of the first biomarkerdriven phase III trial ever done in HCC, that reported negative results for tivantinib in patients with MET-high HCC in 2018 $8^{[7]}$, the quest for personalized approaches is still underway within newer studies that may finally provide a conceptual frame for precision medicine in this hard-to-treat malignancy. Similar approaches could also take advantage from next generation sequencing (NGS) platforms that were recently presented as a useful tool to individualize available targeted therapies in HCC patients ${ }^{[8]}$. Nevertheless, the clinical value of molecular profiling still needs to be demonstrated given that only few patients could receive targeted treatments matching with potentially actionable alterations identified by NGS ${ }^{[8]}$.

Meanwhile, different strategies directed against relevant angiogenesis pathways have provided valuable therapeutic options in the management of advanced HCC. Indeed, a continuous dependence upon pro-angiogenic pathways is typical for HCC and it is reflected by an abnormal hypervascularity well known by the radiologist. This is mainly due to a hypoxic tumor microenvironment (TME) being a major determinant for hypoxia-inducible factor- 1 transcription, that in turn leads to the over-production of vascular endothelial growth factor (VEGF). From a clinical 
standpoint, these peculiar aspects render HCC rather unique in comparisons with other cancers $^{[9]}$ and have long been proven useful for either HCC diagnosis or embolization therapies.

More than a decade ago, the approval of the multikinase inhibitor sorafenib has paved the way of anti-angiogenic therapies targeting VEGF and the VEGF receptors (VEGFRs) in the treatment of advanced HCC patients, not amenable to curative treatments ${ }^{[10]}$. In addition to sorafenib, the therapeutic armamentarium for the frontline setting has been recently expanded with lenvatinib, which is a different multikinase inhibitor, still retaining anti-angiogenic properties. As reported in the overall survival analysis (OS) of the REFLECT trial, lenvatinib is non-inferior to sorafenib in untreated patients with advanced HCC ${ }^{[11]}$.

However, intolerance or resistance to frontline sorafenib (or lenvatinib) may become major issues eventually leading to treatment failure. Whereas sorafenib targets encompass both drivers of cancer cell proliferation and the TME, such pharmacological complexity has greatly hampered the search for predictive markers and, arguably, the identification of resistance mechanisms. Nevertheless, after a decade with unsatisfactory results, three novel compounds sharing peculiar VEGFRs inhibition profiles have been recently reported superior when compared to placebo for OS in the second-line setting. These include regorafenib, cabozantinib (both belonging to the multikinase inhibitors class) and ramucirumab (a monoclonal antibody that targets VEGFR 2 signaling).

Aim of this review is to summarize current knowledge on the aforementioned agents and their role in the treatment of HCC patients who failed or are intolerant to sorafenib.

\section{Regorafenib}

Regorafenib is an orally administered tyrosine-kinase inhibitor that blocks the activity of several receptors such as VEGFR 1, 2, and 3, tyrosine-protein kinase receptor, and platelet-derived growth factor receptor $\beta^{[12]}$. Based on the crucial role of angiogenesis in HCC development and progression, and on the results of a phase II study in patients with well-preserved liver function (Child-Pugh class A) progressing on sorafenib ${ }^{[13]}$, regorafenib has been investigated in a large international phase III trial

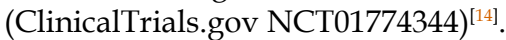

The RESORCE trial was a multicenter, randomized, double-blind, placebocontrolled phase III trial assessing the role of regorafenib in patients affected by HCC progressing on sorafenib. Principal inclusion criteria were Barcelona clinic liver cancer (BCLC) stage B or C, preserved liver function (Child-Pugh class A), Eastern Cooperative Oncology Group (ECOG) performance status (PS) 0 or 1. Pathologic confirmation of diagnosis was not mandatory for patients with confirmed cirrhosis. Patients should have been treated with sorafenib at a minimum dose of $400 \mathrm{mg}$ daily for at least 20 of the $28 \mathrm{~d}$ before discontinuation and should have stopped sorafenib no more than $10 \mathrm{wk}$ before randomization. Reason for sorafenib discontinuation had to be documented radiologic progression, while patients intolerant to sorafenib or who had stopped sorafenib due to toxicity were not allowed to be included in the trial.

The trial randomized 573 patients from May 2013 to December 2015. Patients were randomized in a 2:1 ratio to receive regorafenib $(n=379)$ or placebo $(n=194)$ and were stratified by geographical origin (Asia vs rest of world), ECOG PS (0 vs 1), blood alpha-fetoprotein (AFP) levels (<400 ng/mL vs $\geq 400 \mathrm{ng} / \mathrm{mL}$ ), extrahepatic disease (yes vs no), and macrovascular invasion (yes vs no).

Patients in the two groups were well-balanced for baseline characteristics, including sex, race, geographical origin, stage of disease, stage of liver dysfunction, and etiology. The proportion of patients with Asiatic origin was $38 \%$. The treatment consisted in four $40 \mathrm{mg}$ tablets of regorafenib $(160 \mathrm{mg})$ orally or matching placebo once daily for 21 consecutive days, followed by $7 \mathrm{~d}$ of rest in 4 -wk cycles. Treatment could be interrupted for disease progression according to modified RECIST $(\mathrm{mRECIST})^{[15]}$, clinical progression, death, unacceptable toxicity, or decision by the investigator. Tumor assessments were performed every $6 \mathrm{wk}$ for the first 8 cycles and every $12 \mathrm{wk}$ thereafter. The primary end-point of the study was OS in the intent-totreat population (ITT). Secondary endpoints were progression-free survival (PFS), time to treatment progression (TTP), objective response rate (ORR), and disease control rate (DCR) assessed by the investigators using mRECIST and RECIST v.1.1 ${ }^{[16]}$. Further endpoints were safety, pharmacokinetics (PK), biomarker evaluation, and quality of life (QOL).

At the data cut-off for final analysis (February 29, 2016), among patients who started treatment $(n=567), 309(83 \%)$ in the regorafenib arm and $183(95 \%)$ in the placebo arm discontinued the study drug. The most frequent reason for treatment discontinuation was disease progression. Median treatment duration was 3.6 mo with regorafenib and 1.9 mo with placebo. With a median follow-up of 7 mo, median OS 
was 10.6 mo in the regorafenib arm vs $7.8 \mathrm{mo}$ in the placebo arm [hazard ratio $(\mathrm{HR})=$ $0.6395 \%$ confidence interval $(\mathrm{CI}): 0.50-0.79, P<0.0001]$. The same survival gain was confirmed in the updated survival analysis performed almost 1 year after the first one $(10.7 \text { mo vs } 7.9 \text { mo, HR }=0.61, P<0.0001)^{[17]}$. Median PFS by mRECIST was 3.1 mo in regorafenib arm and $1.5 \mathrm{mo}$ in the placebo arm. Regorafenib was superior to placebo in all the efficacy endpoints and similar results have been demonstrated by RECIST 1.1 assessment (Table 1$)^{[18]}$.

The safety population included 567 patients (99\% of randomized patients), 374 in the regorafenib group and 193 in the placebo group. All patients in the regorafenib arm and $93 \%$ of patients in the placebo arm had at least one adverse event (AE), graded using NCI-CTCAE version 4.03. These AEs were deemed related to the study drug in $93 \%$ of patients on regorafenib and $52 \%$ of patients on placebo (Table 2). Most frequently observed grade 3-4 AEs were hypertension (15\% of patients on regorafenib vs $5 \%$ of patients on placebo), hand-foot skin reaction (HFSR) (13\% vs $1 \%$ ), fatigue (9\% vs $5 \%$ ), and diarrhea ( $3 \%$ vs none). According to prior sorafenib dosing, grade $\geq 3$ HFSR, fatigue, anorexia, and increased bilirubin were slightly higher in the group of patients that received $<800 \mathrm{mg}$ compared with $800 \mathrm{mg}$, as last dose, while no difference was observed in rates of other treatment-emergent adverse events (TEAEs). Therefore, the last sorafenib dose may not predict the onset of TEAEs occurring with regorafenib ${ }^{[19]}$. Serious AEs (SAEs) and death rates were similar in the two groups; SAEs were attributed to the study drug in $10 \%$ of patients on regorafenib and $3 \%$ of patients on placebo. Grade 5 AEs occurring within $30 \mathrm{~d}$ after the last dose of treatment were observed in $13 \%$ of patients in regorafenib patients and $20 \%$ in placebo arm and were deemed related to the study drug in 7 patients on regorafenib and 2 patients on placebo (both liver failure). Regorafenib was interrupted or reduced in $68 \%$ of patients and discontinued in $25 \%$ of patients due to AEs, while $31 \%$ of patients on placebo interrupted or reduced treatment and $19 \%$ of patients on placebo discontinued due to AEs. The most common AEs responsible for regorafenib discontinuation were aspartate aminotransferase (AST) or alanine aminotransferase increase (2\% and 1\%) and HFSR (2\%).

Quality of life during the study was assessed by several questionnaires (Functional Assessment of Cancer Therapy-General and Hepatobiliary, EQ-5D, EQ-VAS) and no statistically significant changes in QOL were detected between the two treatment arms.

Further exploratory data showed that the sequence of sorafenib followed by regorafenib achieved a median OS of $26 \mathrm{mo}^{[19]}$. The efficacy of regorafenib was assessed according to the pattern of progression on prior sorafenib ${ }^{[20]}$ and to the last sorafenib dose ${ }^{[19]}$. Regorafenib was shown to provide significant survival benefits regardless of the pattern of progression and the last sorafenib dose, although the development of new distant metastases or vascular invasion was confirmed to be a negative prognostic factor. Furthermore, a negative correlation between baseline AFP and circulating MET levels and prognosis was confirmed regardless of treatment ${ }^{[21]}$. Of note OS with regorafenib was significantly higher in patients suffering from HFSR $^{[22]}$, and this is in line with the correlation between skin toxicity and prognosis prospectively demonstrated with sorafenib ${ }^{[23]}$.

In subsequent analyses regorafenib population PK (popPK) and exposure-response relationship were studied. PopPK analysis showed that most intrinsic factors had no statistically significant or clinically relevant impact on regorafenib exposure. Only age was found to be related to differences in exposure but the impact on efficacy was considered not significant ${ }^{[24]}$. No statistically significant correlations between exposure and outcomes were identified ${ }^{[2]}$.

Preplanned, retrospective, optional biomarker analyses on archival tumor tissues and plasma samples collected at baseline were performed to identify potential biomarkers correlating with clinical outcome ${ }^{[26]}$. Baseline patient and disease characteristics were similar in the overall RESORCE population and in the plasma biomarker analysis cohorts, while several differences were reported between the overall study population and the tumor biomarker analysis cohorts due to the small sample size. Out of the 573 patients enrolled, only 68 archival tumor samples were collected while plasma samples were available for all the enrolled patients. For the NGS analysis, 23 tumor samples (all in the regorafenib arm) were selected, and 17 were of sufficient quality for analysis. For the immune profiling analysis, 62 samples had sufficient RNA, and 46 were of sufficient quality for analysis (32 in the regorafenib arm, 14 in the placebo arm). The NGS analysis showed mutations in CTNNB1 in 3/10 progressors and 0/7 responders, and VEGFA amplification in $1 / 7$ responders and $0 / 10$ progressors. The immune profiling analysis defined immune gene expression signatures with 3 groups with low (46\%), medium (37\%), and high $(17 \%)$ immune cell scores. However, the small sample size precluded any meaningful conclusions and these results can be considered only hypothesis generating. For the 
Table 1 Efficacy results of the RESORCE phase III trial

\begin{tabular}{|c|c|c|c|c|}
\hline Outcome based on assessment per mRECIST & Regorafenib $n=379(\%)$ & Placebo $n=194(\%)$ & $\mathrm{HR}(95 \% \mathrm{Cl})$ & $P$ value \\
\hline \multicolumn{5}{|l|}{ Response } \\
\hline Complete & $2(1)$ & 0 & - & NR \\
\hline Partial & $38(10)$ & $8(4)$ & - & NR \\
\hline Overall response rate & $40(11)$ & $8(4)$ & - & 0.0047 \\
\hline Stable disease & $206(54)$ & $62(32)$ & - & NR \\
\hline Disease control rate & $247(65)$ & $70(36)$ & - & $<0.0001$ \\
\hline \multicolumn{5}{|l|}{ Overall survival in mo } \\
\hline Median & 10.6 & 7.8 & 0.63 & $<0.0001$ \\
\hline $95 \% \mathrm{CI}$ & $9.1-12.1$ & $6.3-8.8$ & $(0.50-0.79)$ & \\
\hline \multicolumn{5}{|l|}{ Progression-free survival in mo } \\
\hline Median & 3.1 & 1.5 & 0.46 & $<0.0001$ \\
\hline $95 \% \mathrm{CI}$ & $2.8-4.2$ & $1.4-1.6$ & $(0.37-0.56)$ & \\
\hline \multicolumn{5}{|l|}{ Time to progression in mo } \\
\hline Median & 3.2 & 1.5 & 0.44 & $<0.0001$ \\
\hline $95 \% \mathrm{CI}$ & $(2.9-4.2)$ & $(1.4-1.6)$ & $(0.36-0.55)$ & \\
\hline \multicolumn{5}{|l|}{ Outcome based on assessment per RECIST 1.1} \\
\hline \multicolumn{5}{|l|}{ Response } \\
\hline Complete & 0 & 0 & - & NR \\
\hline Partial & $25(7)$ & $5(3)$ & - & NR \\
\hline Overall response rate & $25(7)$ & $5(3)$ & - & 0.02 \\
\hline Stable disease & $223(59)$ & $62(32)$ & - & NR \\
\hline Disease control rate & $249(66)$ & $67(35)$ & - & $<0.0001$ \\
\hline \multicolumn{5}{|l|}{ Progression-free survival in mo } \\
\hline Median & 3.4 & 1.5 & 0.43 & $<0.0001$ \\
\hline $95 \% \mathrm{CI}$ & $2.9-4.2$ & $1.4-1.5$ & $(0.35-0.52)$ & \\
\hline \multicolumn{5}{|l|}{ Time to progression in mo } \\
\hline Median & 3.9 & 1.5 & 0.41 & $<0.0001$ \\
\hline $95 \% \mathrm{CI}$ & $(2.9-4.2)$ & $(1.4-1.6)$ & $(0.34-0.51)$ & \\
\hline
\end{tabular}

Adapted from: Bruix et al ${ }^{[14]}$; Bruix et $a l^{[18]}$. CI: Confidence interval; NR: Not reported; HR: Hazard ratio.

plasma analyses, 499 samples were of sufficient quality for protein analysis (332 in the regorafenib arm, 167 in the placebo arm), and 343 were of sufficient quality for RNA analysis (234 in the regorafenib arm, 109 in the placebo arm). The plasma analyses revealed multiple proteins and miRNAs possibly predictive for OS in patients treated with regorafenib. In particular, they identified 5 OS predictive biomarkers (angiopeietin-1, cystatin B, the latency-associated peptide of transforming growth factor beta1, oxidized low density lipoprotein receptor $1 \mathrm{C}-\mathrm{C}$ motif chemokine ligand 3 ), and 47 TTP predictive biomarkers ${ }^{[26]}$. Finally, an exploratory analysis on 328 whole blood DNA samples identified single nucleotide polymorphisms (SNPs) prognostic for TTP, one of which, in the UGT1A1 gene, was also predictive of regorafenib TTP benefit. Also, two SNPs in the VEGFA gene were identified as having a prognostic or predictive treatment effect on grade $\geq 1 \mathrm{HFSR}^{[27]}$.

Based on the results of the phase III RESORCE trial, regorafenib has been approved by the United States Food and Drug Administration (FDA), the European Medicines Agency (EMA), and many other regulatory agencies for the treatment of patients with advanced HCC previously treated with sorafenib. The recommended dose and schedule for regorafenib in HCC is $160 \mathrm{mg}$ administered orally once daily for $21 \mathrm{~d}$ every $28 \mathrm{~d}$. As mentioned above, prior sorafenib tolerance and preserved liver function (Child-Pugh class A) remain crucial to determine the eligibility status for treatment with regorafenib.

\section{Cabozantinib}

Cabozantinib is an oral multikinase inhibitor of several receptors including MET, VEGFR 1, 2, 3, AXL (GAS6 receptor), and RET. Other known targets of cabozantinib include ROS1, TRKA, TRKB, TYRO3, MER, KIT, and FLT-3 ${ }^{[28]}$. Based on preclinical studies in HCC models demonstrating the role of VEGFRs, MET, and AXL in tumor 


\begin{tabular}{|c|c|c|c|c|c|c|c|c|c|c|c|c|}
\hline & \multicolumn{6}{|c|}{ Adverse events, $n(\%)$} & \multicolumn{6}{|c|}{ Treatment-related adverse events, $n(\%)$} \\
\hline & \multirow{2}{*}{\multicolumn{3}{|c|}{$\begin{array}{l}\text { Regorafenib } \\
n=374\end{array}$}} & \multirow{2}{*}{\multicolumn{3}{|c|}{$\begin{array}{l}\text { Placebo } \\
n=193\end{array}$}} & \multirow{2}{*}{\multicolumn{3}{|c|}{$\begin{array}{l}\text { Regorafenib } \\
n=374\end{array}$}} & \multirow{2}{*}{\multicolumn{3}{|c|}{$\begin{array}{l}\text { Placebo } \\
n=193\end{array}$}} \\
\hline & & & & & & & & & & & & \\
\hline & Any G & G 3 & G 4 & Any G & G 3 & G 4 & Any G & G 3 & G 4 & Any G & G 3 & G 4 \\
\hline Any $\mathrm{AE}$ & $374(100)$ & $208(56)$ & $40(11)$ & $179(93)$ & $61(32)$ & $14(7)$ & $346(93)$ & $173(46)$ & $14(4)$ & $100(52)$ & $31(16)$ & $1(1)$ \\
\hline HFSR & $198(53)$ & 47 (13) & NA & $15(8)$ & $1(1)$ & NA & $196(52)$ & 47 (13) & NA & $13(7)$ & $1(1)$ & NA \\
\hline Diarrhea & $155(41)$ & $12(3)$ & 0 & $29(15)$ & 0 & NA & $125(33)$ & $9(2)$ & 0 & $18(9)$ & 0 & 0 \\
\hline Fatigue & $151(40)$ & $34(9)$ & NA & $61(32)$ & $9(5)$ & NA & $110(29)$ & $24(6)$ & NA & 37 (19) & $3(2)$ & NA \\
\hline Hypertension & $116(31)$ & $56(15)$ & $1(<1)$ & $12(6)$ & $9(5)$ & 0 & $87(23)$ & $48(13)$ & $1(<1)$ & $9(5)$ & $6(3)$ & 0 \\
\hline Anorexia & $116(31)$ & $10(3)$ & 0 & $28(15)$ & $4(2)$ & 0 & $88(24)$ & $10(3)$ & 0 & $12(6)$ & 0 & 0 \\
\hline Increased bilirubin & $108(29)$ & $37(10)$ & $2(1)$ & $34(18)$ & $15(8)$ & $6(3)$ & $70(19)$ & $24(6)$ & $1(<1)$ & $7(4)$ & $4(2)$ & 0 \\
\hline Increased AST & $92(25)$ & $37(10)$ & $4(1)$ & $38(20)$ & $19(10)$ & $3(2)$ & $48(13)$ & $16(4)$ & $3(1)$ & $15(8)$ & $9(5)$ & $1(1)$ \\
\hline Fever & $72(19)$ & 0 & 0 & $14(7)$ & 0 & 0 & $14(4)$ & 0 & 0 & $4(2)$ & 0 & 0 \\
\hline Nausea & $64(17)$ & $2(1)$ & NA & $26(13)$ & 0 & NA & $40(11)$ & $1(<1)$ & NA & $13(7)$ & 0 & NA \\
\hline Increased ALT & $55(15)$ & $10(3)$ & $2(1)$ & $22(11)$ & $5(3)$ & 0 & $29(8)$ & $6(2)$ & $2(1)$ & $8(4)$ & $2(1)$ & 0 \\
\hline Weight loss & $51(14)$ & $7(2)$ & NA & $9(5)$ & 0 & NA & $27(7)$ & $4(1)$ & NA & $3(2)$ & 0 & NA \\
\hline Oral mucositis & 47 (13) & $4(1)$ & 0 & $6(3)$ & $1(1)$ & 0 & $42(11)$ & $4(1)$ & 0 & $5(3)$ & $1(1)$ & 0 \\
\hline Vomiting & $47(13)$ & $3(1)$ & 0 & $13(7)$ & $1(1)$ & 0 & $27(7)$ & $1(<1)$ & 0 & $5(3)$ & 0 & 0 \\
\hline Cough & 40 (11) & $1(<1)$ & NA & $14(7)$ & 0 & NA & $4(1)$ & 0 & NA & $2(1)$ & 0 & NA \\
\hline Hypophosphatemia & $37(10)$ & $30(8)$ & $2(1)$ & $4(2)$ & $3(2)$ & 0 & $22(6)$ & $16(4)$ & $2(1)$ & $2(1)$ & $1(1)$ & 0 \\
\hline Hoarseness & $39(10)$ & 0 & NA & $1(1)$ & 0 & NA & $34(9)$ & 0 & NA & 0 & 0 & NA \\
\hline
\end{tabular}

Adapted from: Bruix et al ${ }^{[14]}$. G: Grade; AE: Adverse event; HFSR: Hand-foot skin reaction; ALT: Alanine aminotransferase; AST: Aspartate aminotransferase; NA: Not applicable.

progression ${ }^{[29]}$, of MET in acquired resistance to antiangiogenic therapy including sorafenib ${ }^{[7,30-32]}$, and on the results of a phase II randomized discontinuation trial in $\mathrm{HCC}^{[33]}$, cabozantinib has been tested in the multicenter, randomized, double-blind, placebo-controlled phase III CELESTIAL trial (ClinicalTrials.gov NCT01908426) ${ }^{[34]}$. The CELESTIAL trial enrolled patients with pathologic diagnosis of HCC not amenable to curative treatment, preserved liver function (Child-Pugh class A), and good PS (ECOG 0 or 1). Enrolled patients had received previous treatment with sorafenib, they could have received up to two prior systemic regimens for advanced HCC and had progressed following at least one prior systemic treatment. From September 2013 to September 2017, 773 patients were randomized. At the time of the second interim analysis of OS (data cutoff of June 1, 2017) 707 patients were randomized $(2: 1$ ratio) to receive cabozantinib $(n=470)$ or placebo $(n=237)$ and constitute the ITT population for efficacy analyses. Randomization was stratified by disease etiology (HBV with or without HCV vs HCV without HBV vs other), region (Asia vs other), macrovascular invasion and/or extrahepatic disease (yes vs no). Baseline patient characteristics were well-balanced between the two treatment arms. All patients had received prior treatment with sorafenib, and 192 patients $(27 \%)$ had received two previous systemic therapies for advanced HCC. Patients received 60-mg cabozantinib tablets or matching placebo once per day continuously. Tumor assessment was performed every $8 \mathrm{wk}$ according to RECIST $1.1^{[16]}$. Patients received treatment until loss of clinical benefit (treatment beyond radiographic progression was allowed) or unacceptable AEs. The primary endpoint was OS in the ITT population, secondary endpoints were PFS and ORR assessed by the investigators using RECIST $1.1^{[16]}$. At the time of data cutoff, 73 patients $(16 \%)$ in the cabozantinib arm and 26 patients $(11 \%)$ in the placebo arm were still on treatment. The most common reason for discontinuation was radiographic disease progression. One hundred and twenty-three patients $(26 \%)$ in the cabozantinib arm and 78 patients $(33 \%)$ in the placebo arm received post-study systemic or liver-directed therapy. Median OS was 10.2 mo (95\% CI: 9.1-12.0) in the cabozantinib arm vs 8.0 mo (95\% CI: 6.8-9.4) in the placebo arm, with a HR of 0.76 (95\% CI: 0.63-0.92) and a $P$ value of 0.005 . This value met the criterion for statistical significance at the second interim analysis (stopping boundary $P=0.02$ ), which included 484 deaths, corresponding to $78 \%$ of the 621 deaths planned for the prespecified final analysis. Cabozantinib performed better 
than placebo in all the efficacy endpoints (Table 3$)^{[34-35]}$. Preplanned and exploratory analyses confirmed the superiority of cabozantinib compared to placebo in all subgroups of patients. In the subgroup of patients who had received only sorafenib as previous systemic treatment, median OS was 11.3 mo in the cabozantinib group and 7.2 mo in the placebo group ( $\mathrm{HR}=0.70,95 \% \mathrm{CI}$ : $0.55-0.88)$, and median PFS was 5.5 mo in the cabozantinib group and 1.9 mo in the placebo group $(\mathrm{HR}=0.40,95 \% \mathrm{CI}$ : 0.32-0.50). Cabozantinib improved clinical outcomes irrespective of prior sorafenib duration ${ }^{[36]}$, age (cutoff 65 years) ${ }^{[37]}$, baseline AFP values ${ }^{[38]}$, prior transarterial chemoembolization (TACE) ${ }^{[39]}$, tumor burden ${ }^{[40]}$, and in patients with HBV etiology ${ }^{[41]}$. Furthermore, $47 \%$ of patients on cabozantinib compared to $11 \%$ of patients on placebo had any reduction in target lesions, and among patients with elevated baseline AFP levels, $23 \%$ of patients on cabozantinib compared to $5 \%$ of patients on placebo achieved $\geq 50 \%$ reduction in AFP levels ${ }^{[35]}$. AFP response rate, defined as $\geq 20 \%$ decrease in AFP level from baseline at week 8, was higher with cabozantinib vs placebo and was associated with longer OS and PFS with cabozantinib ${ }^{[42]}$. Although different cutoffs were adopted, these findings are in line with previous reports suggesting a benefit from systemic treatments in patients achieving an AFP response ${ }^{[43]}$.

The safety population included 704 patients who started treatment, 467 in the cabozantinib group and 237 in the placebo group. Median duration of treatment was 3.8 mo with cabozantinib and 2 mo with placebo. Ninety-nine percent of patients who received cabozantinib and $92 \%$ of patients who received placebo had $\geq 1$ AE (graded according to NCI-CTCAE version 4.0 ), and $68 \%$ of patients on cabozantinib and $32 \%$ of patients on placebo had $\geq 1$ grade 3-4 AE. Most common grade 3-4 AEs were palmar-plantar erythrodysesthesia (PPE) (17\% of patients on cabozantinib vs $0 \%$ of patients on placebo), hypertension ( $16 \%$ vs $2 \%)$, increased AST level (12\% vs $7 \%)$, fatigue ( $10 \%$ vs $4 \%$ ), and diarrhea (10\% vs $2 \%$ ) (Table 4$)$. SAEs were reported in $50 \%$ of patients in the cabozantinib arm and in $37 \%$ of patients in the placebo arm. Grade 5 AEs occurring within $30 \mathrm{~d}$ after the last dose of treatment, mostly disease progression, were observed in $12 \%$ of patients in both arms and were deemed related to the study drug in 6 patients on cabozantinib and in 1 patient on placebo. Dose reductions (to 40 $\mathrm{mg}$ and then to $20 \mathrm{mg}$ daily) and discontinuations due to AEs occurred in $62 \%$ and $16 \%$ of patients on cabozantinib and in $13 \%$ and $3 \%$ of patients on placebo, respectively. AEs leading to treatment discontinuation in $>1.0 \%$ of patients in the cabozantinib group were PPE, fatigue, decreased appetite, diarrhea, and nausea. Median average daily dose was $35.8 \mathrm{mg}$ for cabozantinib and $58.9 \mathrm{mg}$ for placebo, and median time to first dose reduction was $38 \mathrm{~d}$ in the cabozantinib arm ${ }^{[34]}$. The safety results for cabozantinib reported in the exploratory analyses were consistent with the results in the overall study population ${ }^{[36-41]}$. Of note, albeit patients $\geq 65$ years more frequently discontinued treatment due to AEs, rate of dose reductions and median average daily dose were similar irrespective of age ${ }^{[37]}$. Grade 3-4 AEs were similar for HBV-positive patients and for patients with prior TACE compared to the overall study population and to patients without prior TACE, respectively ${ }^{[39-41]}$. Also, a post hoc QOL analysis estimated the incremental quality-adjusted life-years (QALYs) accrued with cabozantinib. Although cabozantinib was associated with an initial, small reduction in health utility compared to placebo, the difference reduced with dose adjustments and considering the overall within-trial health utility experience, cabozantinib was associated with a clinically and statistically significant benefit in mean QALY ${ }^{[44]}$. Finally, a popPK analysis showed that PK of cabozantinib in HCC patients was similar to that observed for other cancer types and healthy volunteers, and that HCC patients with mild and moderate hepatic dysfunction had consistent exposure with the patients of normal liver function ${ }^{[45]}$.

Based on the results of the phase III CELESTIAL trial, cabozantinib has been approved by the EMA and the FDA for the treatment of patients with HCC who have been previously treated with sorafenib. The recommended dose and schedule for cabozantinib in HCC is $60 \mathrm{mg}$, administered orally once daily (tablet formulation).

Given a strong preclinical rationale showing the effect of cabozantinib on immunemediated killing of tumor cells and immune TME permissiveness ${ }^{[46]}$, ongoing studies are testing cabozantinib in combination with immune checkpoints inhibitors. Notably, the multicenter, randomized, open-label, controlled phase III COSMIC-312 trial (ClinicalTrials.gov NCT03755791) is evaluating the efficacy and safety of cabozantinib in combination with atezolizumab $v$ s the standard of care sorafenib in patients with advanced HCC who have not received previous systemic therapy.

\section{Ramucirumab}

Ramucirumab is a recombinant human IgG1 monoclonal antibody that interferes with high affinity with the extracellular domain of VEGFR 2, blocking the binding of its ligands VEGF-A, VEGF-C, and VEGF-D, that play an important role in tumor 
Table 3 Efficacy results of the CELESTIAL phase III trial

\begin{tabular}{|c|c|c|c|c|}
\hline Outcome & Cabozantinib & Placebo & HR & $P$ value \\
\hline Intent to treat population & $n=470(\%)$ & $n=237(\%)$ & $(95 \% \mathrm{Cl})$ & \\
\hline Overall response rate & & & & 0.009 \\
\hline Partial response & $18(4)$ & $1(<1)$ & - & \\
\hline $95 \% \mathrm{CI}$ & $(2.3-6.0)$ & $(0.0-2.3)$ & & \\
\hline Stable disease & $282(60)$ & $78(33)$ & - & NR \\
\hline Disease control rate & $300(64)$ & $79(33)$ & - & NR \\
\hline \multicolumn{5}{|l|}{ Overall survival in mo } \\
\hline Median & 10.2 & 8.0 & 0.76 & 0.005 \\
\hline $95 \% \mathrm{CI}$ & $9.1-12.0$ & $6.8-9.4$ & $(0.63-0.92)$ & \\
\hline \multicolumn{5}{|l|}{ Progression-free survival in mo } \\
\hline Median & 5.2 & 1.9 & 0.44 & $<0.001$ \\
\hline $95 \% \mathrm{CI}$ & $4.0-5.5$ & $1.9-1.9$ & $(0.36-0.52)$ & \\
\hline Time to progression in mo & & & & NR \\
\hline Median & 5.4 & 1.9 & 0.41 & \\
\hline $95 \% \mathrm{CI}$ & $(4.0-5.6)$ & $(1.9-1.9)$ & $(0.34-0.49)$ & \\
\hline Patients who have only received sorafenib as prior therapy & $n=335(\%)$ & $n=174(\%)$ & HR $(95 \% \mathrm{CI})$ & $P$ value \\
\hline \multicolumn{5}{|l|}{ Overall survival in mo } \\
\hline Median & 11.3 & 7.2 & 0.70 & NR \\
\hline $95 \% \mathrm{CI}$ & $9.5-13.9$ & $5.8-9.3$ & $(0.55-0.88)$ & \\
\hline \multicolumn{5}{|l|}{ Progression-free survival in mo } \\
\hline Median & 5.5 & 1.9 & 0.40 & NR \\
\hline $95 \% \mathrm{CI}$ & $4.6-5.7$ & $1.9-1.9$ & $(0.32-0.50)$ & \\
\hline
\end{tabular}

Adapted from: Abou-Alfa et al ${ }^{[34]}$; Merle et $l^{[35]}$; Kelley et $a l^{[36]}$. CI: Confidence interval; NR: Not reported; HR: Hazard ratio.

angiogenesis and tumor growth ${ }^{[47]}$. Two phase I trials evaluated ramucirumab in order to define the maximum-tolerated dose with doses ranging from $2 \mathrm{mg} / \mathrm{kg}$ per week to $20 \mathrm{mg} / \mathrm{kg}$ per $3 \mathrm{wk}$ intravenously and two patients with advanced HCC experienced disease control longer than $6 \mathrm{mo}^{[47-48]}$. These results provided the rationale for a phase II study that confirmed the antitumor activity with an acceptable safety profile of ramucirumab $8 \mathrm{mg} / \mathrm{kg}$ per $2 \mathrm{wk}$ in first-line $\mathrm{HCC}^{[49]}$. The phase III REACH trial (ClinicalTrials.gov NCT01140347) evaluated ramucirumab $8 \mathrm{mg} / \mathrm{kg}$ per $2 \mathrm{wk} v \mathrm{~s}$ placebo in 565 patients with advanced HCC as second-line treatment following sorafenib. With a median OS of 9.2 mo in the ramucirumab arm and of 7.6 mo in the placebo arm $(\mathrm{HR}=0.87,95 \% \mathrm{CI}: 0.72-1.05, P=0.14)$, this trial did not meet its primary endpoint. However, in the prespecified analysis of the subgroup of patients with baseline AFP levels $\geq 400 \mathrm{ng} / \mathrm{mL}(n=250)$, ramucirumab showed a significant survival benefit, with a median OS of 7.8 mo vs $4.2 \mathrm{mo}(\mathrm{HR}=0.67, P=0.006)$, with a good safety profile. In addition, the $\mathrm{REACH}$ trial confirmed in the overall study population the negative prognostic role of baseline elevated AFP levels ${ }^{[50]}$.

In HCC the AFP value is included in several prognostic scoring systems ${ }^{[51-53]}$ and a concentration $>400 \mathrm{ng} / \mathrm{mL}$ has been associated with worse prognosis ${ }^{[50,54]}$. Also, increased VEGFR expression and angiogenesis have been demonstrated in patients with HCC and elevated AFP concentration ${ }^{[2,55,56]}$.

Based on these data and on the results achieved in the REACH trial in patients with high baseline AFP levels, ramucirumab was further tested in the phase III multicenter, randomized, double-blind, placebo-controlled REACH-2 trial (ClinicalTrials.gov NCT02435433 $)^{[57]}$.

The REACH-2 trial enrolled patients with histologic or cytologic diagnosis of HCC or, in the absence of histologic confirmation, with cirrhosis and HCC, BCLC stage B, or $\mathrm{C}$ disease not suitable for locoregional therapy, preserved liver function (ChildPugh class A), and good PS (ECOG 0-1), AFP levels $\geq 400 \mathrm{ng} / \mathrm{mL}$, progressing on or intolerant to first-line treatment with sorafenib. From July 26, 2015, to August 30, 2017, 292 patients were randomly assigned (2:1 ratio), 197 to the ramucirumab group and 95 to the placebo group. Randomization was stratified by geographical region [region 1 (Americas, Europe, Australia, Israel) vs region 2 (Asia, excluding Japan) vs region 3 (Japan)], macrovascular invasion (yes vs no), and ECOG PS (0 vs 1 ). Patients 


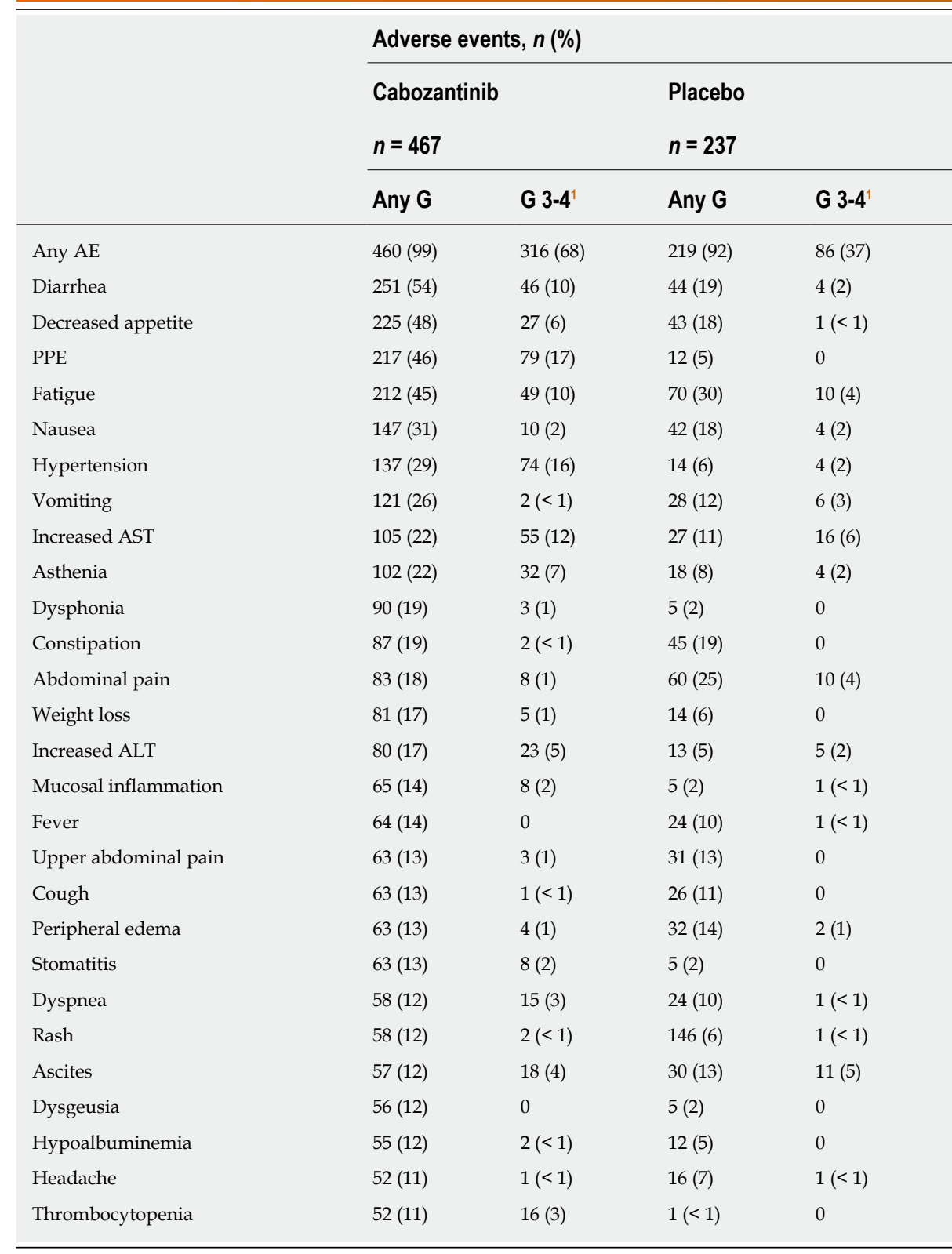

${ }^{1}$ Mostly grade 3; Adapted from: Abou-Alfa et al ${ }^{[34]}$. G: Grade; AE: Adverse event; PPE: Palmar-plantar erythrodysesthesia; AST: Aspartate aminotransferase; ALT: Alanine aminotransferase.

received ramucirumab $8 \mathrm{mg} / \mathrm{kg}$ or placebo intravenously every $14 \mathrm{~d}$ until disease progression, unacceptable toxicity, or withdrawal of consent. Tumor assessment was performed by the investigators every $6 \mathrm{wk}$ according to RECIST 1.1 during the first 6 mo of treatment, and every $9 \mathrm{wk}$ thereafter. Patient-reported outcomes were assessed at baseline, every $6 \mathrm{wk}$, and at treatment discontinuation with the Functional Assessment of Cancer Therapy Hepatobiliary Symptom Index 8 (FHSI-8), which specifically evaluates the most frequently observed symptoms of patients with hepatobiliary malignancies: lack of energy, nausea, pain, weight loss, back pain, fatigue, jaundice, and stomach pain or discomfort ${ }^{[58]}$. Serum AFP levels were measured at baseline, every $6 \mathrm{wk}$ during the treatment period, and at the end of the treatment period.

The primary endpoint of REACH-2 trial was OS, secondary endpoints were PFS, ORR, TTP, safety, time to deterioration in scores on the FHSI-8, and time to deterioration in ECOG PS. Efficacy analyses were conducted by ITT, safety analyses were done in all patients who received at least one dose of study drug. Baseline patient characteristics were well-balanced between the two treatment arms, except for baseline AFP levels that were higher in the ramucirumab group [ $2741 \mathrm{ng} / \mathrm{mL}$ (IQR 1178-11861) in the placebo group vs $3920 \mathrm{ng} / \mathrm{mL}$ (IQR 1175-20000) in the 
ramucirumab group]. Median duration of prior sorafenib was 4.1 mo in both groups, and 50 patients $(17 \%)$ discontinued sorafenib due to intolerance. At the time of data cutoff, March 15, 2018, 281 patients were off treatment, and 11 patients in the ramucirumab group were still receiving therapy; 206 patients $(71 \%)$ had disease progression, and 221 (76\%) had died. Median OS was 8.5 mo (95\% CI: 7.0-10.6) in the ramucirumab arm vs 7.3 mo (95\%CI: 5.4-9.1) in the placebo arm, with a HR of 0.71 (95\%CI: 0.53-0.95) and a $P$ value of 0.0199 . Ramucirumab also significantly improved PFS (2.8 vs 1.6 mo, HR = 0.45, 95\% CI: 0.339-0.603, $P<0.0001)$, and DCR $(59.9 \%$ vs $38.9 \%, P=0.0006)$. These results were confirmed in almost all predefined subgroups (Table 5).

Median duration of treatment was $12 \mathrm{wk}$ with ramucirumab and $8 \mathrm{wk}$ with placebo. Treatment discontinuations due to any AEs (graded according to NCICTCAE version 4.0$)$ (18\% vs $11 \%)$ and to treatment-related AEs (11\% vs $3 \%)$ of any grade were more frequent in the ramucirumab group compared to the placebo group. Dose reductions ( $5 \%$ vs $2 \%$ ), delays (6\% vs $3 \%)$, and omissions ( $29 \%$ vs $11 \%$ ) due to AEs were more common in the ramucirumab arm than in the placebo arm. Most common AEs of any grade in the ramucirumab group were fatigue $(27 \%)$, peripheral edema $(25 \%)$, hypertension $(25 \%)$, and decreased appetite $(23 \%)$. Hypertension $(12 \%$ vs $4 \%$ ) and hyponatremia ( $5 \%$ vs $2 \%$ ) were the only grade $\geq 3$ AEs reported in $\geq 5 \%$ of patients (Table 6). SAEs occurred in $35 \%$ of patients in the ramucirumab group and $29 \%$ in the placebo group. Grade 5 AEs occurring within $30 \mathrm{~d}$ after the last dose of treatment were observed in $20 \%$ of patients in the ramucirumab arm and $17 \%$ of patients in the placebo arm, and were deemed related to the study drug in 4 patients on ramucirumab ( 3 liver failure and 1 arterial thromboembolic event) and in no patient on placebo. FHSI- 8 was completed in $99 \%$ of patients at baseline and $67 \%$ at the end of treatment in both groups. Median time to deterioration of FHSI- 8 scores ( 3.7 mo vs $2.8 \mathrm{mo}, P=0.238)$ and ECOG PS $(P=0.77)$ were not different between the ramucirumab and placebo arms, although the number of events did not allow a meaningful statistical assessment of ECOG PS deterioration ${ }^{[58]}$.

An exploratory analysis investigated the potential relationship between changes in AFP during treatment and efficacy in terms of survival, considering AFP response defined as $\geq 20 \%$ decrease from baseline. Ramucirumab was shown to prolong time to AFP progression and radiographic TTP and to slow the rate of AFP increase compared to placebo. AFP response was significantly higher in the ramucirumab arm compared to the placebo arm $(42 \%$ vs $11 \%, P<0.0001)$. Also, regardless of treatment OS was longer in patients with AFP response (13.5 mo in AFP responders vs 6.7 mo in non-responders, $\mathrm{HR}=0.47, P<0.0001)$, and changes in AFP levels were associated with radiographic TTP ( 3 mo in AFP responders vs 1.6 mo in non-responders, HR = $0.43, P<0.0001)^{[59]}$.

A preplanned pooled meta-analysis of individual data of patients $(n=542)$ enrolled in the REACH-2 trial and patients with AFP $\geq 400 \mathrm{ng} / \mathrm{mL}$ enrolled in the REACH trial (ramucirumab, $n=316$; placebo, $n=226$ ) confirmed significant improvements in OS (median 8.1 vs $5.0 \mathrm{mo}$ with placebo, $\mathrm{HR}=0.69,95 \% \mathrm{CI}$ : $0.57-0.84, P=0.0002$ ), PFS (median 2.8 vs $1.5 \mathrm{mo}$ with placebo, $\mathrm{HR}=0.57,95 \% \mathrm{CI}$ : $0.47-0.69, P<0.0001$ ), and DCR (56.3\% vs $37.2 \%$ with placebo, $P<0.0001$ ). Of note, median baseline AFP levels were lower in the REACH-2 trial compared to those in the above mentioned cohort of the REACH trial [3394 ng/mL (IQR 1177-16812) vs $5736 \mathrm{ng} / \mathrm{mL}$ (IQR 1322-291000)] ${ }^{[58]}$. The same pooled analysis showed a reduction in disease-related symptoms with ramucirumab compared to placebo, with a significantly delay in FHSI-8 time to deterioration ( 3 mo with ramucirumab vs 1.9 mo with placebo $)^{[60]}$. Also, the pooled analysis confirmed the efficacy and safety results regardless of etiology, including $\mathrm{HCV}, \mathrm{HBV}$, and other ${ }^{[61]}$, and in Japanese patients ${ }^{[62]}$. Finally, an exploratory analysis evaluated the prognostic utility of Child-Pugh score $v$ s albumin-bilirubin (ALBI) grade, showing a similar prognostic utility of the two scoring system and a higher incidence of liver AEs in patients with a high score in either system, and confirming the efficacy of ramucirumab in patients with ALBI score 1 or 2 or Child-Pugh score 5 or $6^{[63]}$.

Based on these results ramucirumab, pending approval, will be a new treatment option for patients previously treated with sorafenib and with baseline elevated AFP levels. The recommended dose and schedule for ramucirumab is $8 \mathrm{mg} / \mathrm{kg}$ intravenously every $14 \mathrm{~d}$.

\section{CONCLUSION}

Despite numerous negative trial results in the second-line setting, the current clinical scenario is quickly expanding with the anticipated availability of three antiangiogenic agents-regorafenib, cabozantinib, and ramucirumab-shown to prolong OS in recent phase III second-line trials. In contrast, preliminary data from a phase III trial of pembrolizumab ${ }^{[64]}$ suggest that single-agent immune checkpoint inhibitors might 
Table 5 Efficacy results of the REACH-2 phase III trial

\begin{tabular}{|c|c|c|c|c|}
\hline Outcome & Ramucirumab $n=197(\%)$ & Placebo $n=95(\%)$ & $\mathrm{HR}(95 \% \mathrm{Cl})$ & $P$ value \\
\hline \multicolumn{5}{|l|}{ Response } \\
\hline Complete & 0 & 0 & - & NR \\
\hline Partial & $9(4.6)$ & $1(1.1)$ & - & NR \\
\hline Overall response rate & $9(4.6)$ & $1(1.1)$ & - & 0.1697 \\
\hline Stable disease & $109(55.3)$ & $36(37.9)$ & - & NR \\
\hline Disease control rate & $118(59.9)$ & $37(38.9)$ & - & 0.0006 \\
\hline Overall survival in mo & & & $0.71(0.53-0.94)$ & 0.0199 \\
\hline Median & 8.5 & 7.3 & & \\
\hline $95 \% \mathrm{CI}$ & $7.0-10.6$ & $5.4-9.1$ & & \\
\hline Progression-free survival in mo & & & $0.45(0.33-0.60)$ & $<0.0001$ \\
\hline Median & 2.8 & 1.6 & & \\
\hline $95 \% \mathrm{CI}$ & $2.8-4.1$ & $1.5-2.7$ & & \\
\hline Time to progression in mo & & & $0.42(0.31-0.58)$ & $<0.0001$ \\
\hline Median & 3.0 & 1.6 & & \\
\hline $95 \% \mathrm{CI}$ & $(2.8-4.2)$ & $(1.5-2.7)$ & & \\
\hline
\end{tabular}

Adapted from: Zhu et al ${ }^{[57]}$. CI: Confidence interval; NR: Not reported; HR: Hazard ratio.

not be superior to placebo in patients who had received prior sorafenib. In fact, despite numerically longer OS and PFS in the pembrolizumab arm of the KEYNOTE240 study, the statistical significance per pre-specified statistical plan was not met. Pending additional details from KEYNOTE-240 that need to be considered, these disappointing results do not necessarily imply a dead end for immunotherapy studies in HCC.

Rather, combinations of immune checkpoint inhibitors and anti-angiogenics may represent a sound evolution of current treatment options. In this respect, it is predicted that some agents may also move from the second-line to a frontline setting, as it is the case for current phase I trials of regorafenib plus pembrolizumab (ClinicalTrials.gov NCT03347292), or cabozantinib plus nivolumab as neoadjuvant treatment (ClinicalTrials.gov NCT03299946). In principle, robust preclinical data do support similar strategies aiming to improve the effectiveness of immunotherapy converting an immunosuppressive milieu into an immunosupportive one ${ }^{[65]}$. However, most clinical studies are still in their very early stages of development, while other studies are already making their way into more advanced phase III contexts (ClinicalTrials.gov NCT03755791).

For the time being, in the absence of additional agents looming in the spotlight of placebo-controlled studies, an anti-VEGFR strategy is overall regarded as the only one increasing survival, and thereby establishing a standard of care after prior sorafenib treatment. Still, when it comes to specific treatment choices, the debate remains open as no direct comparative studies testing regorafenib, cabozantinib, and ramucirumab are available. With the notable exception of ramucirumab (whose efficacy could not be proven in patients with low AFP levels), there is no approved biomarker that can aid patient selection, and this observation clearly speaks to the huge translational efforts needed. As in other oncology settings, clinical factors informing treatment selection should include first-line therapy, tolerance, and duration of response to prior treatment. In fact, inclusion and exclusion criteria provided by each clinical study protocol should be an additional aid for the selection of the most adequate second-line agent. For instance, poor tolerability of prior sorafenib excludes an individual patient from treatment with regorafenib. Similarly, low AFP levels clearly contraindicate ramucirumab. In view of a treatment sequencing that includes up to three lines, consistent with CELESTIAL study ${ }^{[34]}$, one may consider cabozantinib as a third-line treatment. Even patients' clinical conditions by the time of disease progression, liver function, and the adverse events profiles are variables that need to be considered in the decision-making process.

Further, will the results of well-conducted clinical trials fulfill the expectations of the real-world setting? This is not a trivial point, and this will undoubtedly pose additional questions, especially in light of a limited benefit of sorafenib previously reported in a cohort of Medicare beneficiaries ${ }^{[6]}$.

The scientific community is witnessing a turning point for our knowledge of the 


\begin{tabular}{|c|c|c|c|c|c|c|c|c|c|c|c|c|}
\hline & \multicolumn{6}{|c|}{ Adverse events, $n(\%)$} & \multicolumn{6}{|c|}{ Treatment-related adverse events, $n(\%)$} \\
\hline & \multirow{2}{*}{\multicolumn{3}{|c|}{$\begin{array}{l}\text { Ramucirumab } \\
n=197\end{array}$}} & \multirow{2}{*}{\multicolumn{3}{|c|}{$\begin{array}{l}\text { Placebo } \\
n=95\end{array}$}} & \multirow{2}{*}{\multicolumn{3}{|c|}{$\begin{array}{l}\text { Ramucirumab } \\
n=197\end{array}$}} & \multirow{2}{*}{\multicolumn{3}{|c|}{$\begin{array}{l}\text { Placebo } \\
n=95\end{array}$}} \\
\hline & & & & & & & & & & & & \\
\hline & Any G & G 3 & G 4 & Any $\mathbf{G}$ & G 3 & G 4 & Any G & G 3 & G 4 & Any G & G3 & G 4 \\
\hline Fatigue & $54(27)$ & $7(4)$ & NA & $16(17)$ & $3(3)$ & NA & $28(14)$ & $2(1)$ & NA & $5(5)$ & 0 & NA \\
\hline Peripheral edema & $50(25)$ & $3(2)$ & 0 & $13(14)$ & 0 & 0 & $15(8)$ & $2(1)$ & 0 & $5(5)$ & 0 & 0 \\
\hline Decreased appetite & $46(23)$ & $3(2)$ & 0 & $19(20)$ & $1(1)$ & 0 & $21(11)$ & 0 & NA & $4(4)$ & 0 & 0 \\
\hline Abdominal pain & $39(20)$ & $3(2)$ & NA & $12(13)$ & $2(2)$ & NA & $8(4)$ & $1(1)$ & $1(<1)$ & $3(3)$ & 0 & NA \\
\hline Nausea & $37(19)$ & 0 & NA & $11(12)$ & 0 & NA & $23(12)$ & 0 & 0 & $2(2)$ & 0 & NA \\
\hline Diarrhea & $32(16)$ & 0 & 0 & $13(14)$ & $1(1)$ & 0 & $14(7)$ & 0 & $1(<1)$ & $5(5)$ & $1(1)$ & 0 \\
\hline Headache & $28(14)$ & 0 & NA & $5(5)$ & $1(1)$ & NA & $12(6)$ & 0 & $3(1)$ & 0 & 0 & NA \\
\hline Constipation & $27(14)$ & $1(1)$ & 0 & $19(20)$ & $1(1)$ & 0 & $3(2)$ & $1(1)$ & 0 & $3(3)$ & 0 & 0 \\
\hline Insomnia & $21(11)$ & 0 & NA & $6(6)$ & $1(1)$ & NA & $1(1)$ & 0 & NA & 0 & 0 & NA \\
\hline Pyrexia & $20(10)$ & 0 & 0 & $3(3)$ & 0 & 0 & $4(2)$ & 0 & $2(1)$ & $1(1)$ & 0 & 0 \\
\hline Vomiting & $20(10)$ & 0 & 0 & $7(7)$ & 0 & 0 & $5(3)$ & 0 & NA & $1(1)$ & 0 & 0 \\
\hline Bleeding or hemorrhage events & $48(24)$ & $9(5)$ & $1(1)$ & $12(13)$ & $2(2)$ & $1(1)$ & $21(11)$ & $1(<1)$ & 0 & $5(5)$ & 0 & $1(1)$ \\
\hline Epistaxis & $27(14)$ & $1(1)$ & 0 & $3(3)$ & 0 & 0 & $14(7)$ & 0 & 0 & $2(2)$ & 0 & 0 \\
\hline GI hemorrhage events & $12(6)$ & $7(4)$ & 0 & $5(5)$ & $2(2)$ & 0 & $1(1)$ & $1(1)$ & 0 & 0 & 0 & 0 \\
\hline Hepatic hemorrhage events & $1(1)$ & 0 & $1(1)$ & 0 & 0 & 0 & 0 & 0 & 0 & 0 & 0 & 0 \\
\hline Pulmonary hemorrhage events & $5(2)$ & $1(1)$ & 0 & 0 & 0 & 0 & 0 & 0 & 0 & 0 & 0 & 0 \\
\hline Hypertension & $49(25)$ & $25(13)$ & 0 & $12(13)$ & $5(5)$ & 0 & $32(16)$ & $15(8)$ & 0 & $6(6)$ & $2(2)$ & 0 \\
\hline Proteinuria & $40(20)$ & $4(2)$ & 0 & $4(4)$ & 0 & 0 & $27(14)$ & $4(2)$ & 0 & $3(3)$ & 0 & 0 \\
\hline Arterial TE events & $5(3)$ & 0 & $1(1)$ & $1(1)$ & 0 & 0 & $4(2)$ & 0 & $1(1)$ & 0 & 0 & 0 \\
\hline Venous TE events & $2(1)$ & 0 & 0 & $2(2)$ & $1(1)$ & 0 & $1(1)$ & 0 & 0 & $1(1)$ & 0 & 0 \\
\hline GI perforation & $2(1)$ & $2(1)$ & 0 & $2(2)$ & $2(2)$ & 0 & $1(1)$ & $1(1)$ & 0 & 0 & 0 & 0 \\
\hline Congestive heart failure & $1(1)$ & 0 & 0 & $1(1)$ & $1(1)$ & 0 & 0 & 0 & 0 & 0 & 0 & 0 \\
\hline Fistula & $1(1)$ & 0 & 0 & 0 & 0 & 0 & 0 & 0 & 0 & 0 & 0 & 0 \\
\hline Liver injury or failure & $78(40)$ & $28(14)$ & $4(2)$ & $28(29)$ & $14(15)$ & $1(1)$ & $17(9)$ & $3(2)$ & 0 & $2(2)$ & 0 & 0 \\
\hline Ascites & $35(18)$ & $7(4)$ & 0 & $7(7)$ & $2(2)$ & 0 & $4(2)$ & $1(1)$ & 0 & $1(1)$ & 0 & 0 \\
\hline Hepatic encephalopathy & $8(4)$ & $5(3)$ & $1(1)$ & 0 & 0 & 0 & $2(1)$ & $1(1)$ & 0 & 0 & 0 & 0 \\
\hline Infusion related reactions & $17(9)$ & $28(14)$ & 0 & $3(3)$ & 0 & 0 & $13(7)$ & 0 & 0 & $2(2)$ & 0 & 0 \\
\hline
\end{tabular}

Adapted from: Zhu et al ${ }^{[57]}$. G: Grade; AE: Adverse event; NA: Not applicable; GI: Gastrointestinal; TE: Thromboembolic.

genetic and immunologic landscape of HCC. Encouraging efficacy signals are now emerging from the use of second-line anti-angiogenic agents after sorafenib. Arguably, from a clinical perspective, the next challenge will be the implementation of well-designed studies that include sound correlative translational investigations. This is a great opportunity to bridge the enormous gap between clinical practice and basic science still existing in the field of HCC research.

\section{REFERENCES}

1 Ferlay J, Soerjomataram I, Dikshit R, Eser S, Mathers C, Rebelo M, Parkin DM, Forman D, Bray F. Cancer incidence and mortality worldwide: sources, methods and major patterns in GLOBOCAN 2012. Int J Cancer 2015; 136: E359-E386 [PMID: 25220842 DOI: 10.1002/ijc.29210]

2 Zucman-Rossi J, Villanueva A, Nault JC, Llovet JM. Genetic Landscape and Biomarkers of Hepatocellular Carcinoma. Gastroenterology 2015; 149: 1226-1239.e4 [PMID: 26099527 DOI: 10.1053/j.gastro.2015.05.061]

3 Vitale A, Peck-Radosavljevic M, Giannini EG, Vibert E, Sieghart W, Van Poucke S, Pawlik TM. Personalized treatment of patients with very early hepatocellular carcinoma. J Hepatol 2017; 66: 412-423 [PMID: 27677712 DOI: 10.1016/j.jhep.2016.09.012]

4 Llovet JM, Zucman-Rossi J, Pikarsky E, Sangro B, Schwartz M, Sherman M, Gores G. Hepatocellular carcinoma. Nat Rev Dis Primers 2016; 2: 16018 [PMID: 27158749 DOI: 10.1038/nrdp.2016.18]

5 Llovet JM, Montal R, Sia D, Finn RS. Molecular therapies and precision medicine for hepatocellular carcinoma. Nat Rev Clin Oncol 2018; 15: 599-616 [PMID: 30061739 DOI: 10.1038/s41571-018-0073-4] 
6 Sia D, Villanueva A, Friedman SL, Llovet JM. Liver Cancer Cell of Origin, Molecular Class, and Effects on Patient Prognosis. Gastroenterology 2017; 152: 745-761 [PMID: 28043904 DOI: 10.1053/j.gastro.2016.11.048]

7 Rimassa L, Assenat E, Peck-Radosavljevic M, Pracht M, Zagonel V, Mathurin P, Rota Caremoli E, Porta C, Daniele B, Bolondi L, Mazzaferro V, Harris W, Damjanov N, Pastorelli D, Reig M, Knox J, Negri F, Trojan J, López López C, Personeni N, Decaens T, Dupuy M, Sieghart W, Abbadessa G, Schwartz B, Lamar M, Goldberg T, Shuster D, Santoro A, Bruix J. Tivantinib for second-line treatment of MET-high, advanced hepatocellular carcinoma (METIV-HCC): a final analysis of a phase 3, randomised, placebocontrolled study. Lancet Oncol 2018; 19: 682-693 [PMID: 29625879 DOI:

10.1016/S1470-2045(18)30146-3]

8 Harding JJ, Nandakumar S, Armenia J, Khalil DN, Albano M, Ly M, Shia J, Hechtman JF, Kundra R, El Dika I, Do RK, Sun Y, Kingham TP, D'Angelica MI, Berger MF, Hyman DM, Jarnagin W, Klimstra DS, Janjigian YY, Solit DB, Schultz N, Abou-Alfa GK. Prospective Genotyping of Hepatocellular Carcinoma: Clinical Implications of Next-Generation Sequencing for Matching Patients to Targeted and Immune Therapies. Clin Cancer Res 2019; 25: 2116-2126 [PMID: 30373752 DOI: 10.1158/1078-0432.CCR-18-2293]

9 Sun HC, Tang ZY, Li XM, Zhou YN, Sun BR, Ma ZC. Microvessel density of hepatocellular carcinoma: its relationship with prognosis. J Cancer Res Clin Oncol 1999; 125: 419-426 [PMID: 10394963 DOI: 10.1007/s004320050296]

10 Llovet JM, Ricci S, Mazzaferro V, Hilgard P, Gane E, Blanc JF, de Oliveira AC, Santoro A, Raoul JL, Forner A, Schwartz M, Porta C, Zeuzem S, Bolondi L, Greten TF, Galle PR, Seitz JF, Borbath I, Häussinger D, Giannaris T, Shan M, Moscovici M, Voliotis D, Bruix J; SHARP Investigators Study Group. Sorafenib in advanced hepatocellular carcinoma. N Engl J Med 2008; 359: 378-390 [PMID: 18650514 DOI: 10.1056/NEJMoa0708857]

11 Kudo M, Finn RS, Qin S, Han KH, Ikeda K, Piscaglia F, Baron A, Park JW, Han G, Jassem J, Blanc JF, Vogel A, Komov D, Evans TRJ, Lopez C, Dutcus C, Guo M, Saito K, Kraljevic S, Tamai T, Ren M, Cheng AL. Lenvatinib vs sorafenib in first-line treatment of patients with unresectable hepatocellular carcinoma: a randomised phase 3 non-inferiority trial. Lancet 2018; 391: 1163-1173 [PMID: 29433850 DOI: 10.1016/S0140-6736(18)30207-1]

12 Wilhelm SM, Dumas J, Adnane L, Lynch M, Carter CA, Schütz G, Thierauch KH, Zopf D. Regorafenib (BAY 73-4506): a new oral multikinase inhibitor of angiogenic, stromal and oncogenic receptor tyrosine kinases with potent preclinical antitumor activity. Int J Cancer 2011; 129: 245-255 [PMID: 21170960 DOI: $10.1002 /$ ijc.25864]

13 Bruix J, Tak WY, Gasbarrini A, Santoro A, Colombo M, Lim HY, Mazzaferro V, Wiest R, Reig M, Wagner A, Bolondi L. Regorafenib as second-line therapy for intermediate or advanced hepatocellular carcinoma: multicentre, open-label, phase II safety study. Eur J Cancer 2013; 49: 3412-3419 [PMID: 23809766 DOI: 10.1016/j.ejca.2013.05.028]

14 Bruix J, Qin S, Merle P, Granito A, Huang YH, Bodoky G, Pracht M, Yokosuka O, Rosmorduc O, Breder V, Gerolami R, Masi G, Ross PJ, Song T, Bronowicki JP, Ollivier-Hourmand I, Kudo M, Cheng AL, Llovet JM, Finn RS, LeBerre MA, Baumhauer A, Meinhardt G, Han G; RESORCE Investigators. Regorafenib for patients with hepatocellular carcinoma who progressed on sorafenib treatment (RESORCE): a randomised, double-blind, placebo-controlled, phase 3 trial. Lancet 2017; 389: 56-66 [PMID: 27932229 DOI: 10.1016/S0140-6736(16)32453-9]

15 Lencioni R, Llovet JM. Modified RECIST (mRECIST) assessment for hepatocellular carcinoma. Semin Liver Dis 2010; 30: 52-60 [PMID: 20175033 DOI: 10.1055/s-0030-1247132]

16 Eisenhauer EA, Therasse P, Bogaerts J, Schwartz LH, Sargent D, Ford R, Dancey J, Arbuck S, Gwyther S, Mooney M, Rubinstein L, Shankar L, Dodd L, Kaplan R, Lacombe D, Verweij J. New response evaluation criteria in solid tumours: revised RECIST guideline (version 1.1). Eur J Cancer 2009; 45: 228247 [PMID: 19097774 DOI: 10.1016/j.ejca.2008.10.026]

17 Bruix J, Merle P, Granito A, Huang YP, Bodoky G, Yokosuka O, Rosmorduc O, Breder V, Gerolami R, Masi G, Ross PJ, Qin S, Song T, Bronowicki JP, Ollivier-Hourmand T, Kudo M, Le Berren MA, Baumhauer A, Meinhardt G, Han G. On behalf of the Resorce Investigators. Updated overall survival (OS) analysis from the international, phase 3, randomized, placebo-controlled RESORCE trial of regorafenib for patients with hepatocellular carcinoma (HCC) who progressed on sorafenib treatment. Ann Oncol 2017; 28: I40 [DOI: 10.1093/annonc/mdx262.008]

18 Bruix J, Merle P, Granito A, Huang YP, Bodoky G, Pracht M, Yokosuka O, Rosmorduc O, Breder V, Gerolami R, Masi G, Ross PJ, Qin S, Song T, Bronowicki JP, Ollivier-Hourmand T, Kudo M, Le Berren MA, Baumhauer A, Meinhardt G, Han G; cki JP, Ollivier-Hourmand I, Kudo M, Baumhauer A, LeBerre MA, Meinhardt G, Han G. On behalf of the RESORCE Investigators. Comparison of modified (m)RECIST and RECIST 1.1 assessments in the phase 3 RESORCE trial comparing regorafenib and placebo in patients with hepatocellular carcinoma who progressed during sorafenib treatment. $J$ Hepatol 2017; 66: S451-S452 [DOI: 10.1016/S0168-8278(17)31281-3]

19 Finn RS, Merle P, Granito A, Huang YH, Bodoky G, Pracht M, Yokosuka O, Rosmorduc O, Gerolami R, Caparello C, Cabrera R, Chang C, Sun W, LeBerre MA, Baumhauer A, Meinhardt G, Bruix J. Outcomes of sequential treatment with sorafenib followed by regorafenib for HCC: Additional analyses from the phase III RESORCE trial. J Hepatol 2018; 69: 353-358 [PMID: 29704513 DOI: 10.1016/j.jhep.2018.04.010]

20 Bruix J, Merle P, Granito A, Huang YP, Bodoky G, Pracht M, Yokosuka O, Breder V, Gerolami R, Masi G, Ross PJ, Qin S, Song T, Bronowicki JP, Ollivier-Hourmand T, Kudo M, Baumhauer A, Han G. And On Behalf of RESORCE Investigators. Survival by pattern of tumor progression during prior sorafenib (SOR) treatment in patients with hepatocellular carcinoma (HCC) in the phase III RESORCE trial comparing second-line treatment with regorafenib (REG) or placebo. J Clin Oncol 2017; 35: 229-229 [DOI: 10.1200/JCO.2017.35.4_suppl.229]

21 Teufel M, Köchert K, Meinhardt G, Bruix J. Efficacy of regorafenib (REG) in patients with hepatocellular carcinoma (HCC) in the phase III RESORCE trial according to alpha-fetoprotein (AFP) and c-Met levels as predictors of poor prognosis. J Clin Oncol 2017; 35: 4078-4078 [DOI: 10.1200/JCO.2017.35.15 suppl.4078]

22 Bruix J, Merle P, Granito A, Huang YP, Bodoky G, Pracht M, Rosmorduc O, Breder V, Gerolami R, Masi G, Ross PJ, Qin S, Song T, Bronowicki JP, Ollivier-Hourmand T, Kudo M, Xu L, Le Berren MA, Baumhauer A, Meinhardt G, Han G. And On Behalf of RESORCE Investigators. Hand-foot skin reaction (HFSR) and overall survival (OS) in the phase 3 RESORCE trial of regorafenib for treatment of 
hepatocellular carcinoma (HCC) progressing on sorafenib. J Clin Oncol 2018; 36: 412-412 [DOI: 10.1200/JCO.2018.36.4_suppl.412]

23 Reig M, Torres F, Rodriguez-Lope C, Forner A, LLarch N, Rimola J, Darnell A, Ríos J, Ayuso C, Bruix J. Early dermatologic adverse events predict better outcome in HCC patients treated with sorafenib. $J$ Hepatol 2014; 61: 318-324 [PMID: 24703956 DOI: 10.1016/j.jhep.2014.03.030]

24 Ploeger B, Cleton A, Keunecke A, Bruix J, Meinhardt G. Population pharmacokinetics (popPK) to evaluate the effect of intrinsic and extrinsic factors on regorafenib exposure in regorafenib studies, including patients with hepatocellular carcinoma (HCC). J Clin Oncol 2017; 35: 320-320 [DOI: 10.1200/JCO.2017.35.4 suppl.320]

25 Solms A, Reinecke I, Fiala-Buskies S, Keunecke A, Drenth HJ, Bruix J, Meinhardt G, Cleton A, Ploeger B. Exposure-response relationship of regorafenib efficacy in patients with hepatocellular carcinoma. Eur J Pharm Sci 2017; 109S: S149-S153 [PMID: 28549676 DOI: 10.1016/j.ejps.2017.05.050]

26 Teufel M, Seidel H, Köchert K, Meinhardt G, Finn RS, Llovet JM, Bruix J. Biomarkers Associated With Response to Regorafenib in Patients With Hepatocellular Carcinoma. Gastroenterology 2019; 156: 17311741 [PMID: 30738047 DOI: 10.1053/j.gastro.2019.01.261]

27 Köchert K, Meinhardt G, Teufel M. Analysis of single-nucleotide polymorphisms (SNPs) in the phase 3 RESORCE trial of regorafenib vs placebo in patients with hepatocellular carcinoma (HCC). Ann Oncol 2018; 29: viii236 [DOI: 10.1093/annonc/mdy282.084]

28 Yakes FM, Chen J, Tan J, Yamaguchi K, Shi Y, Yu P, Qian F, Chu F, Bentzien F, Cancilla B, Orf J, You A, Laird AD, Engst S, Lee L, Lesch J, Chou YC, Joly AH. Cabozantinib (XL184), a novel MET and VEGFR2 inhibitor, simultaneously suppresses metastasis, angiogenesis, and tumor growth. Mol Cancer Ther 2011; 10: 2298-2308 [PMID: 21926191 DOI: 10.1158/1535-7163.MCT-11-0264]

29 Goyal L, Muzumdar MD, Zhu AX. Targeting the HGF/c-MET pathway in hepatocellular carcinoma. Clin Cancer Res 2013; 19: 2310-2318 [PMID: 23388504 DOI: 10.1158/1078-0432.CCR-12-2791]

30 Santoro A, Rimassa L, Borbath I, Daniele B, Salvagni S, Van Laethem JL, Van Vlierberghe H, Trojan J, Kolligs FT, Weiss A, Miles S, Gasbarrini A, Lencioni M, Cicalese L, Sherman M, Gridelli C, Buggisch P, Gerken G, Schmid RM, Boni C, Personeni N, Hassoun Z, Abbadessa G, Schwartz B, Von Roemeling R, Lamar ME, Chen Y, Porta C. Tivantinib for second-line treatment of advanced hepatocellular carcinoma: a randomised, placebo-controlled phase 2 study. Lancet Oncol 2013; 14: 55-63 [PMID: 23182627 DOI: 10.1016/S1470-2045(12)70490-4]

31 Rimassa L, Abbadessa G, Personeni N, Porta C, Borbath I, Daniele B, Salvagni S, Van Laethem JL, Van Vlierberghe H, Trojan J, De Toni EN, Weiss A, Miles S, Gasbarrini A, Lencioni M, Lamar ME, Wang Y, Shuster D, Schwartz BE, Santoro A. Tumor and circulating biomarkers in patients with second-line hepatocellular carcinoma from the randomized phase II study with tivantinib. Oncotarget 2016; 7: 7262272633 [PMID: 27579536 DOI: 10.18632/oncotarget.11621]

32 Firtina Karagonlar Z, Koc D, Iscan E, Erdal E, Atabey N. Elevated hepatocyte growth factor expression as an autocrine c-Met activation mechanism in acquired resistance to sorafenib in hepatocellular carcinoma cells. Cancer Sci 2016; 107: 407-416 [PMID: 26790028 DOI: 10.1111/cas.12891]

33 Kelley RK, Verslype C, Cohn AL, Yang TS, Su WC, Burris H, Braiteh F, Vogelzang N, Spira A, Foster P, Lee Y, Van Cutsem E. Cabozantinib in hepatocellular carcinoma: results of a phase 2 placebo-controlled randomized discontinuation study. Ann Oncol 2017; 28: 528-534 [PMID: 28426123 DOI: 10.1093/annonc/mdw651]

34 Abou-Alfa GK, Meyer T, Cheng AL, El-Khoueiry AB, Rimassa L, Ryoo BY, Cicin I, Merle P, Chen Y, Park JW, Blanc JF, Bolondi L, Klümpen HJ, Chan SL, Zagonel V, Pressiani T, Ryu MH, Venook AP, Hessel C, Borgman-Hagey AE, Schwab G, Kelley RK. Cabozantinib in Patients with Advanced and Progressing Hepatocellular Carcinoma. N Engl J Med 2018; 379: 54-63 [PMID: 29972759 DOI: 10.1056/NEJMoa1717002]

35 Merle P, Rimassa L, Ryoo B, Cicin I, Harris W, Banu E, Sarker D, Tan B, Van Vlierberghe H, Sen S, Love C, Cheng A, Meyer T, Kelley R, Abou-Alfa G. Assessment of tumor response, AFP response, and time to progression in the phase 3 CELESTIAL trial of cabozantinib vs placebo in advanced hepatocellular carcinoma (HCC). Ann Oncol 2018; 29: v104 [DOI: 10.1093/annonc/mdy 149.010]

36 Kelley RK, Ryoo BY, Merle P, Park JW, Bolondi L, Chan SL, Lim HY, Baron AD, Parnis F, Knox J, Cattan S, Yau TC, Lougheed J, Milwee S, El-Khoueiry A, Cheng AL, Meyer T, Abou-Alfa GK. Outcomes in patients (pts) who had received sorafenib (S) as the only prior systemic therapy in the phase 3 CELESTIAL trial of cabozantinib (C) vs placebo (P) in advanced hepatocellular carcinoma (HCC). $J$ Clin Oncol 2018; 36: 4088-4088 [DOI: 10.1200/JCO.2018.36.15_suppl.4088]

37 Rimassa L, Cicin I, Blanc JF, Klümpen HJ, Zagonel V, Tran A, Kim SCH, Lin ZZ, Tam VC, Hazra S, Mangeshkar M, El-Khoueiry A, Cheng AL, Meyer T, Kelley RK, Abou-Alfa GK. Outcomes based on age in the phase 3 CELESTIAL trial of cabozantinib (C) vs placebo (P) in patients (pts) with advanced hepatocellular carcinoma (HCC). J Clin Oncol 2018; 36: 4090-4090 [DOI: 10.1200/JCO.2018.36.15 suppl.4090]

38 Kelley RK, El-Khoueiry AB, Meyer T, Rimassa L, Merle P, Chan SL, Tran A, Parnis F, Tam VC, Cattan S, Markby DW, Clary DO, Cheng AL, Abou-Alfa GK. Outcomes by baseline alpha-fetoprotein (AFP) levels in the phase III CELESTIAL trial of cabozantinib $(\mathrm{C})$ vs placebo $(\mathrm{P})$ in previously treated advanced hepatocellular carcinoma (HCC). Ann Oncol 2018; 29: viii236 [DOI: 10.1093/annonc/mdy282.085]

39 Yau T, Cheng AL, Meyer T, Ryoo BY, Park JW, Klümpen HJ, Lim HY, Kim S, Knox J, Patel M, ElKhoueiry AB, Kelley RK, Abou-Alfa GK. Outcomes by prior transarterial chemoembolization in the phase 3 CELESTIAL trial of cabozantinib vs placebo in patients with advanced hepatocellular carcinoma. Ann Oncol 2018; 29: viii237-viii238 [DOI: 10.1093/annonc/mdy282.087]

40 Blanc JF, Meyer T, Cheng AL, El-Khoueiry AB, Cicin I, Chen Y, Bolondi L, Dadduzio V, Baron A, Lin ZZ, Adriani J, Kelly RK, Abou-Alfa GK. Assessment of disease burden in the phase 3 CELESTIAL trial of cabozantinib (C) vs placebo (P) in advanced hepatocellular carcinoma (HCC). Ann Oncol 2018; 29: viii237 [DOI: 10.1093/annonc/mdy282.086]

41 Meyer T, Baron A, Gordan J, Blanc JF, Merle P, Park JW, Nemunaitis J, Hubner R, Sharma MR, Chan SL, Chen YH, Rimassa L, Hazra S, Youkstetter J, El-Khoueiry AB, Cheng AL, Kelley RK, Abou-Alfa GK. Outcomes in Patients (pts) with Hepatitis B Virus (HBV) in the Phase 3 CELESTIAL Trial of Cabozantinib (C) vs Placebo (P) in Advanced Hepatocellular Carcinoma (HCC). 12th ILCA Annual Conference, 2018, abstract O-012

42 Kelley RK, Rimassa L, Ryoo BY, Park JW, Blanc JF, Chan SL, Dadduzio V, Yau T, Sen S, Markby DW, Kaldate R, El-Khoueiry AB, Cheng AL, Meyer T, Abou-Alfa GK. Alpha-fetoprotein response and efficacy outcomes in the phase 3 CELESTIAL trial of cabozantinib vs placebo in advanced hepatocellular 
carcinoma. J Clin Oncol 2019; 37: 423-423 [DOI: 10.1200/JCO.2019.37.4 suppl.423]

43 Personeni N, Bozzarelli S, Pressiani T, Rimassa L, Tronconi MC, Sclafani F, Carnaghi C, Pedicini V, Giordano L, Santoro A. Usefulness of alpha-fetoprotein response in patients treated with sorafenib for advanced hepatocellular carcinoma. J Hepatol 2012; 57: 101-107 [PMID: 22414760 DOI: 10.1016/j.jhep.2012.02.016]

44 Abou-Alfa GK, Mollon P, Meyer T, Cheng AL, El-Khoueiry AB, Kelley RK, Baron AD, Benzaghou F, Valcheva V, Hazra S, Mangeshkar M, Freemantle N. Quality-adjusted life years accrued with cabozantinib in patients with advanced hepatocellular carcinoma (aHCC) in the CELESTIAL trial. J Clin Oncol 2019; 37: 207-207 [DOI: 10.1200/JCO.2019.37.4 suppl.207]

45 Nguyen L, Chapel S, Meyer T, Cheng AL, El-Khoueiry AB, Kelley RK, Abou-Alfa GK, Lacy S Integrated population pharmacokinetic modeling of cabozantinib in patients with various cancer types, including hepatocellular carcinoma. J Clin Oncol 2019; 37: 305-305 [DOI: 10.1200/JCO.2019.37.4_suppl.305]

46 Kwilas AR, Ardiani A, Donahue RN, Aftab DT, Hodge JW. Dual effects of a targeted small-molecule inhibitor (cabozantinib) on immune-mediated killing of tumor cells and immune tumor microenvironment permissiveness when combined with a cancer vaccine. J Transl Med 2014; 12: 294 [PMID: 25388653 DOI: 10.1186/s12967-014-0294-y]

47 Spratlin JL, Cohen RB, Eadens M, Gore L, Camidge DR, Diab S, Leong S, O'Bryant C, Chow LQ, Serkova NJ, Meropol NJ, Lewis NL, Chiorean EG, Fox F, Youssoufian H, Rowinsky EK, Eckhardt SG. Phase I pharmacologic and biologic study of ramucirumab (IMC-1121B), a fully human immunoglobulin G1 monoclonal antibody targeting the vascular endothelial growth factor receptor-2. J Clin Oncol 2010; 28: 780-787 [PMID: 20048182 DOI: 10.1200/JCO.2009.23.7537]

48 Chiorean EG, Hurwitz HI, Cohen RB, Schwartz JD, Dalal RP, Fox FE, Gao L, Sweeney CJ. Phase I study of every 2- or 3-week dosing of ramucirumab, a human immunoglobulin G1 monoclonal antibody targeting the vascular endothelial growth factor receptor-2 in patients with advanced solid tumors. Ann Oncol 2015; 26: 1230-1237 [PMID: 25787923 DOI: 10.1093/annonc/mdv144]

49 Zhu AX, Finn RS, Mulcahy M, Gurtler J, Sun W, Schwartz JD, Dalal RP, Joshi A, Hozak RR, Xu Y, Ancukiewicz M, Jain RK, Nugent FW, Duda DG, Stuart K. A phase II and biomarker study of ramucirumab, a human monoclonal antibody targeting the VEGF receptor-2, as first-line monotherapy in patients with advanced hepatocellular cancer. Clin Cancer Res 2013; 19: 6614-6623 [PMID: 24088738 DOI: 10.1158/1078-0432.CCR-13-1442]

50 Zhu AX, Park JO, Ryoo BY, Yen CJ, Poon R, Pastorelli D, Blanc JF, Chung HC, Baron AD, Pfiffer TE, Okusaka T, Kubackova K, Trojan J, Sastre J, Chau I, Chang SC, Abada PB, Yang L, Schwartz JD, Kudo $\mathrm{M} ; \mathrm{REACH}$ Trial Investigators. Ramucirumab $v s$ placebo as second-line treatment in patients with advanced hepatocellular carcinoma following first-line therapy with sorafenib (REACH): a randomised, double-blind, multicentre, phase 3 trial. Lancet Oncol 2015; 16: 859-870 [PMID: 26095784 DOI: 10.1016/S1470-2045(15)00050-9]

51 A new prognostic system for hepatocellular carcinoma: a retrospective study of 435 patients: the Cancer of the Liver Italian Program (CLIP) investigators. Hepatology 1998; 28: 751-755 [PMID: 9731568 DOI: 10.1002/hep.510280322]

52 Borzio M, Dionigi E, Rossini A, Marignani M, Sacco R, De Sio I, Bertolini E, Francica G, Giacomin A, Parisi G, Vicari S, Toldi A, Salmi A, Boccia S, Mitra M, Fornari F. External validation of the ITA.LI.CA prognostic system for patients with hepatocellular carcinoma: A multicenter cohort study. Hepatology 2018; 67: 2215-2225 [PMID: 29165831 DOI: 10.1002/hep.29662]

53 Leung TW, Tang AM, Zee B, Lau WY, Lai PB, Leung KL, Lau JT, Yu SC, Johnson PJ. Construction of the Chinese University Prognostic Index for hepatocellular carcinoma and comparison with the TNM staging system, the Okuda staging system, and the Cancer of the Liver Italian Program staging system: a study based on 926 patients. Cancer 2002; 94: 1760-1769 [PMID: 11920539 DOI: 10.1002/cncr.10384]

54 Silva JP, Gorman RA, Berger NG, Tsai S, Christians KK, Clarke CN, Mogal H, Gamblin TC. The prognostic utility of baseline alpha-fetoprotein for hepatocellular carcinoma patients. J Surg Oncol 2017; 116: 831-840 [PMID: 28743160 DOI: $10.1002 /$ jso.24742]

55 Yamashita T, Forgues M, Wang W, Kim JW, Ye Q, Jia H, Budhu A, Zanetti KA, Chen Y, Qin LX, Tang ZY, Wang XW. EpCAM and alpha-fetoprotein expression defines novel prognostic subtypes of hepatocellular carcinoma. Cancer Res 2008; 68: 1451-1461 [PMID: 18316609 DOI: 10.1158/0008-5472.CAN-07-6013]

56 Shan YF, Huang YL, Xie YK, Tan YH, Chen BC, Zhou MT, Shi HQ, Yu ZP, Song QT, Zhang QY. Angiogenesis and clinicopathologic characteristics in different hepatocellular carcinoma subtypes defined by EpCAM and $\alpha$-fetoprotein expression status. Med Oncol 2011; 28: 1012-1016 [PMID: 20571936 DOI: 10.1007/s12032-010-9600-6]

57 Zhu AX, Kang YK, Yen CJ, Finn RS, Galle PR, Llovet JM, Assenat E, Brandi G, Pracht M, Lim HY, Rau KM, Motomura K, Ohno I, Merle P, Daniele B, Shin DB, Gerken G, Borg C, Hiriart JB, Okusaka T, Morimoto M, Hsu Y, Abada PB, Kudo M; REACH-2 study investigators. Ramucirumab after sorafenib in patients with advanced hepatocellular carcinoma and increased $\alpha$-fetoprotein concentrations (REACH-2): a randomised, double-blind, placebo-controlled, phase 3 trial. Lancet Oncol 2019; 20: 282-296 [PMID: 30665869 DOI: 10.1016/S1470-2045(18)30937-9]

58 Yount S, Cella D, Webster K, Heffernan N, Chang C, Odom L, van Gool R. Assessment of patientreported clinical outcome in pancreatic and other hepatobiliary cancers: the FACT Hepatobiliary Symptom Index. J Pain Symptom Manage 2002; 24: 32-44 [PMID: 12183093 DOI: 10.1016/S0885-3924(02)00422-0]

59 Finn RS, Kudo M, Kang YK, Yen CJ, Galle PR, Llovet JM, Assenat E, Brandi G, Lim HY, Pracht M, Rau KM, Merle P, Motomura K, Ohno I, Daniele B, Shin D, Gerken G, Abada P, Hsu Y, Zhu AX. Ramucirumab (RAM) as second-line treatment in patients with advanced hepatocellular carcinoma (HCC) and elevated baseline $\alpha$-fetoprotein (AFP): An analysis of AFP kinetics in the phase III REACH-2 study. $J$ Clin Oncol 2019; 37: 326-326 [DOI: 10.1200/JCO.2019.37.4 suppl.326]

60 Zhu AX, Finn RS, Galle PR, Llovet JM, Blanc JF, Okusaka T, Chau I, Cella D, Girvan A, Gable J, Bowman L, Hsu Y, Abada PB, Kudo M. Ramucirumab as second-line treatment in patients with advanced hepatocellular carcinoma (HCC) and elevated alpha-fetoprotein (AFP) following first-line sorafenib: Patient reported outcome results across two phase III studies (REACH-2 and REACH). Ann Oncol 2018; 29: viii205-viii270 [DOI: 10.1093/annonc/mdy282]

61 Galle P, Kudo M, Llovet JM, Finn R, Karwal M, Denis P, Kim TY, Yang TS, Zagonel V, Tomasek J, Jean-Marc Phelip JM, Touchefeu Y, Koh SJ, Stirnimann G, Wang C, Widau R, Hsu Y, Abada PB, Zhu A. 
Ramucirumab for patients with advanced hepatocellular carcinoma and elevated alpha-fetoprotein following sorafenib: Outcomes by liver disease aetiology from two randomised, placebo-controlled phase 3 studies (REACH-2 and REACH). J Hepatol 2019; 70: e46 [DOI: 10.1016/S0168-8278(19)30200-4]

62 Kudo M, Okusaka T, Motomura K, Ohno I, Morimoto M, Seo S, Wada Y, Sato S, Yamashita T, Furukawa M, Aramaki T, Nadano S, Ohkawa K, Fujii H, Kudo T, Furuse J, Takai H, Homma G, Yoshikawa R, Zhu AX. Ramucirumab as Second-Line Treatment in Patients With Advanced Hepatocellular Carcinoma and Elevated Alpha-Fetoprotein Following First-Line Sorafenib: Pooled Efficacy and Safety in Japanese Patients Across Two Global Randomized Phase 3 Studies (REACH-2 and REACH). J Clin Oncol 2019; 37: 320-320 [DOI: 10.1200/JCO.2019.37.4 suppl.320]

63 Brandi G, Kudo M, Kang YK, Yen CJ, Finn R, Galle P, Llovet JM, Assenat E, Merle P, Hiriart JB, Chan SL, Palmer D, Wang C, Widau R, Hsu Y, Abada PB, Zhu A. Ramucirumab for patients with hepatocellular carcinoma and elevated alpha-fetoprotein following sorafenib treatment: exploratory analysis of REACH-2 trial results by albumin-bilirubin grade and Child-Pugh score. EASL HCC Summit, 14-16 February 2019, Lisbon, Portugal, abstract OP-07

64 Finn RS, Ryoo BY, Merle P, Kudo M, Bouattour M, Lim HY, Breder VV, Edeline J, Chao Y, Ogasawara S, Yau T, Garrido M, Lam Chan S, Knox JJ, Daniele B, Ebbinghaus S, Chen E, Siegel AB, Zhu AX, Cheng AL. Results of KEYNOTE-240: phase 3 study of pembrolizumab (Pembro) vs best supportive care (BSC) for second line therapy in advanced hepatocellular carcinoma (HCC). J Clin Oncol 2019; 37: 40044004 [DOI: 10.1200/JCO.2019.37.15_suppl.4004]

65 Fukumura D, Kloepper J, Amoozgar Z, Duda DG, Jain RK. Enhancing cancer immunotherapy using antiangiogenics: opportunities and challenges. Nat Rev Clin Oncol 2018; 15: 325-340 [PMID: 29508855 DOI: 10.1038/nrclinonc.2018.29]

66 Sanoff HK, Chang Y, Lund JL, O'Neil BH, Dusetzina SB. Sorafenib Effectiveness in Advanced Hepatocellular Carcinoma. Oncologist 2016; 21: 1113-1120 [PMID: 27185615 DOI: 10.1634/theoncologist.2015-0478] 


\section{DS \\ Baishideng ${ }^{\circledR}$}

Published By Baishideng Publishing Group Inc

7041 Koll Center Parkway, Suite 160, Pleasanton, CA 94566, USA

Telephone: +1-925-2238242

E-mail: bpgoffice@wignet.com

Help Desk:https://www.f6publishing.com/helpdesk

https://www.wjgnet.com

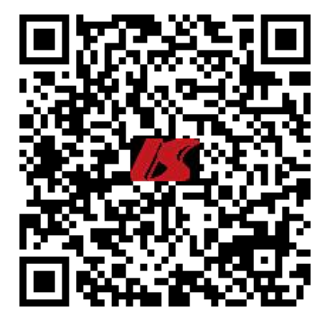

